\title{
Investigating links between students' agency experiences in digital educational interactions, participation and academic performance
}

\author{
Maria Hvid Stenalt
}

Aarhus University

\begin{abstract}
Despite promises of student agency in digital education, student agency is mostly assumed and less researched. This paper provides a way to understand the role of agency in digital interactions, and it explores how students' agency experiences link to student participation and academic performance. In the study, data were collected from nine Danish university students. Students' agency experiences were identified and interpreted using the Adapted Participation Gestalt Framework. Student participation was collected using data from a digital system used for the educational interactions. Students' academic performance was measured using students' self- reported grades. The study makes two key contributions: it identifies the participation gestalt of the interaction in question and maps developments in students' experiences of agency constituting the gestalt; and second, it suggests that students' agency in interactions is associated with grades and participation patterns. Finally, the paper discusses how the findings inform future research.
\end{abstract}

\section{Introduction}

This paper is about student agency in digital higher education, and how we might better understand what student agency means to students' academic performance and student actions in digital contexts of learning. The agency concept originates from the social sciences and can be defined as an individual's capability to engage in intentional, self-defined, meaningful, and autonomous action in circumstances constrained by power relations and structural, contextual factors (e.g., Giddens, 1984). In education, agency or the capacity to act intentionally is of interest as an educational aim (OECD, 2018; Soini, Pietarinen, Toom, \& Pyhältö, 2015; Toom, Pietarinen, Soini, \& Pyhältö, 2017) and a core component of other concepts such as professionalism (Eteläpelto, 2017; Eteläpelto, Vähäsantanen, Hökkä, \& Paloniemi, 2013; Goller \& Paloniemi, 2017).

However, student agency already informs higher education research and strategies. Student-centred learning is essentially about facilitating student agency. According to Klemenčič (2017), depictions of student-centred learning in higher education policy documents suggest that student-centred teaching practices:

- facilitates active learning activities, learning resources, and learner support

- nurtures mutual respect and collaboration within the academic community

- enables and fosters student capabilities to influence their learning experience (including learning environment and pathways)

Given the emphasis on autonomy, choice, and freedoms within SCL teaching practices, Klemenčič (2017) argues that ideas of human agency underpin SCL. In line with this thinking, Damşa \& de Lang (2019) connect student-centred learning environments (SCLE) to agency. Their design principles for SCLE include 'possibilities to access and work with (i.e., structure, organise, process, manipulate) course-relevant knowledge' and providing 'opportunities for differentiated learning trajectories students might want to follow according to their interests, needs, performance, and other important factors' (2019, pp. 16-17). Again, the principles suggested connect to ideas of facilitating an individual's capacity to engage in intentional and meaningful actions.

Providing students with opportunities for developing agency through personalised learning and significant learning experiences is also a central driver for digital education (Tsai, Perrotta, \& Gašević, 2019). Educational technology which is now understood as an essential part of university education has, in particular, been introduced as a way to facilitate student-centred learning and environment. The integration of technology for such purposes has captured the interest of several researchers within the field of educational technology or technology-enhanced learning (for a review of the research, see Kirkwood \& Price, 2014). 
Historically, discussions of agency involve consideration of what enables or hinders agency, including power structures that influence the degree of agency possible. As such, Klemenčič' (2017) interest in agency also includes a focus on students' agentic possibilities (originating outside the individual) and agentic orientation (predispositions and will). Yet, fundamental questions of what hinders or enables student agency in digital interactions have received limited attention in research focusing on educational technology. Selwyn (2016) has claimed that research into higher education uses of technology has focused on improving teaching and learning and, to a less extent, investigated 'the constrained nature of students' agency in negotiating the technological setting of the university' (2016, p. 1008). Yet, in engaging with student agency, we are invited to interrogate assumptions of agency in digital education and to understand further how opportunities for agency or studentcentredness emerge to students.

In exploring that value of student agency in higher education practices, there is also a need for research that explore links between experiences of agency, student actions, and performance. While prior studies of university students mainly have explored agency in itself, only very little is yet known of the link between student learning and student agency (exceptions include Luo et al., 2019; Jääskelä, Poikkeus, et al., 2020). These gabs have been the subject of this paper.

\section{The current study}

The current study seeks to provide insight into the role of agency in student-centred contexts of learning that utilise educational technology. This paper addresses the following research questions:

- How do students' experiences of agency in digital educational interactions develop?

- How are students' participation in digital interactions related to students' experiences of agency?

- To what extent are student participation and experience of agency in educational interactions associated with students' academic performance?

In this study, agency refers to 'student's experience of having access to or being empowered to act through personal, relational, and participatory resources, which allow him/her to engage in purposeful, intentional, and meaningful action and learning in study contexts' (Jääskelä, Poikkeus, et al., 2020, p. 2). However, this study's approach to agency is different from that of Jääskelä, Poikkeus, et al. (2020) utilising a person-/subject-centred approach to agency. Ecological perspectives on learning inform this paper. Here, learning is approached as a result of a social process related to human development (Packer \& Goicoechea, 2000) and 'not a process whereby stable, unchanging things become known by unchanging individuals. Rather, learning comprises changes in the conditions of human life and activity, in which both individuals and environments change' (Damşa \& Jornet, 2016, p. 41). Consequently, the focus on student agency shifts from the autonomous individual to a focus on agents as interactants (Burkitt, 2016) constituted by performative and affective relations. According to Burkitt (2016), relations involve 'a range of interdependencies that are physical, meaningful, emotional, practical, economic, political, and social, all of which involve the various things we do for each other support and constraint, satisfaction or frustration of need, and fulfilling certain roles and functions' (p. 332). This perspective has implications for how to research agency in contexts of learning. Attention to learning as formed through social processes makes is imperative to find ways to explore how agency is relationally constituted and to consider processes that mediate between input and output (Stenalt, 2020; Sun \& Goodyear, 2020).

\section{Materials and methods}

\section{Participants}

This paper report on research with first-semester undergraduate Law students enrolled in a mandatory campusbased course. Approximately 460 students typically enroll in the particular course. Generally, the students are highly motivated to study, enter university with high grades, and do not know each other at the start of the course.

\section{The learning context}

The course is a semester course running from September to December and offered in a Danish university. The face-to-face teaching is conducted through lectures with all students, small class teaching conducted by 
professionals or Faculty members with about 35 students in each class and small group teaching taught by teaching assistants with around 12 students in each class. In the small group teaching, students are offered an additional opportunity to develop competencies required for the final assessment, comprising tasks of identifying issues of concern in a case and applying the appropriate rules to the case using the right arguments. The learning task consists of four main parts: 1) students develop their own assignment and upload the work to the system before coming to class or at the beginning of the class; 2) in class, the teaching assistant explains the correct answer to the assignment, followed by an online process of blind review where students review and comment on two peers' assignments; 3 ) students assess their own work online; 4) students can access the feedback received from peers.

\section{Data collection and instruments}

Participation in the study was voluntary and anonymous. Nine students participated in a semi-structured individual interview at the start of the course and the end of the course. Four students participated in focusgroup interviews at the beginning of the course. The thirteen students were distributed across four of the small group teaching classes, taught by three different teaching assistants. The interviews in the first round each lasted 60 - 90 minutes. During the interview, students were asked to talk about their motivation to study, sense of belonging, approach to learning, and approach to task in question, framed as online peer assessment. The interviews in the second round each lasted 30 - 60 minutes. During the second interview, students were asked to talk about developments and changes to their experiences of the online peer assessment task. This study reports on the nine students participating in both rounds of interviews.

Data on students' agency experience in a teaching-learning interaction

The Adapted Participation Gestalt Framework (APAG) (Stenalt, 2020) was used to measure students' experience of agency in teaching-learning interactions. APAG is initially developed by human-computer interaction researchers (Dalsgaard, Halskov, \& Iversen, 2016) to investigate public digital art installations and later modified for investigations of higher education educational interactions (Stenalt, 2020; Stenalt \& Lassesen, 2017). The advantage of using this framework lies in its underpinning ideas of participation as a social and performative activity (Goffman, 1955), associated with empowerment and emancipation (Halskov \& Hansen, 2015), and constituted by a range of dimensions through which the participation gestalt of the interaction is formed (Dalsgaard et al., 2016; Lim, Stolterman, Jung, \& Donaldson, 2007).

Table 1. The Adapted Participation Gestalt Framework (APAG)

\begin{tabular}{|l|l|l|l|}
\hline Dimension & Subdimension & Description & Rating questions \\
\hline Investment & & $\begin{array}{l}\text { Assesses to what extent students } \\
\text { invest resources and efforts in the } \\
\text { interaction. }\end{array}$ & $\begin{array}{l}\text { To what degree does interacting with } \\
\text { the activity offer opportunities for } \\
\text { engagement (i.e., apply skills and } \\
\text { knowledge and be creative)? } \\
\text { To what degree did you engage with } \\
\text { the activity? }\end{array}$ \\
\hline Sociality & Emotional & $\begin{array}{l}\text { Assesses to what extent students } \\
\text { engage with other people when } \\
\text { interacting. }\end{array}$ & $\begin{array}{l}\text { To what degree does interacting with } \\
\text { the activity offer opportunities for } \\
\text { engaging with peers? } \\
\text { To what degree did you engage with } \\
\text { peers? }\end{array}$ \\
\hline Expressivity & $\begin{array}{l}\text { Assesses to what extent students' } \\
\text { express emotions and feelings } \\
\text { through the interaction. }\end{array}$ & $\begin{array}{l}\text { To what degree does interacting with } \\
\text { the activity allow the expression of } \\
\text { emotions? } \\
\text { To what degree did you share } \\
\text { expressions of emotions? }\end{array}$ \\
& Cognitive & $\begin{array}{l}\text { Assesses to what extent students } \\
\text { express thoughts through the } \\
\text { interaction. }\end{array}$ & $\begin{array}{l}\text { To what degree does interacting with } \\
\text { the activity allow the expression of } \\
\text { thoughts about the activity? } \\
\text { To what degree did you share } \\
\text { expressions of thoughts? }\end{array}$ \\
\hline Persistence & & $\begin{array}{l}\text { Assesses the timespan during } \\
\text { which the interaction or outcome }\end{array}$ & $\begin{array}{l}\text { To what degree is the outcome of the } \\
\text { interaction accessible after the }\end{array}$ \\
\hline
\end{tabular}




\begin{tabular}{|l|l|l|}
\hline & $\begin{array}{l}\text { of the interaction is accessible or } \\
\text { exposed. }\end{array}$ & $\begin{array}{l}\text { activity to yourself, your peers, or } \\
\text { your educator? }\end{array}$ \\
\hline Exposure & $\begin{array}{l}\text { Assesses the visibility of the } \\
\text { participant or level of attention } \\
\text { that the participant attracts during } \\
\text { or after the interaction. }\end{array}$ & $\begin{array}{l}\text { To what degree is your contribution } \\
\text { to the activity identifiable to } \\
\text { yourself, your peers, or your } \\
\text { educator? }\end{array}$ \\
\hline
\end{tabular}

In each round of the interviews, a rating activity was adopted to collect information on students' agency and their participatory experience using APAG (see Table 1) with a 5-point scale from 1 to 5 ( $1=$ to a low degree, $5=$ to a high degree).

\section{Data on student participation}

Data from the digital system used for online peer assessment was extracted and used to collect information on student participation. In this study, information about the number of times students participated successfully in the learning task was used. All but one student accepted the use of individual digital data for research.

Data on students' academic performance

Final grades measured students' academic performance. The grades were self-reported by students and collected through email or text chat. All students accepted the optional reporting of their final grade.

\section{Data analysis}

Data from the interviews related to the rating activity were identified and analysed using the principles and techniques from qualitative data analysis (Miles, Huberman, \& Saldäna 1994) to examine how students' agency experiences emerge. This part of the study is reported in Stenalt (2020). This paper extends prior research by identifying developments in students' first and second scores of their agency experiences and by mapping these with students' participation and academic performance.

\section{Results and discussion}

\section{What constitutes students' agency experiences}

Generally, students provided the highest scores to the aspects of the interaction relating to individual cognitive work (investment). Thus, cognitive aspects, in particular, formed the gestalt of the interaction. Students referred to high scores of investment as comprising opportunities to practice what they were expected to learn from the course and expected to master in the final assessment, such as being able to identify and apply the correct rules to a case and present a case in writing. However, providing feedback to peers was viewed as less beneficial and lowered the scores given to the dimension. Although giving feedback to peers was framed by educators as an opportunity to become familiar with the academic criteria, limited trust among students in their own and peers' knowledge, little time for providing feedback, and limited autonomy in the provision of feedback hindered investment. As a result, students would hand-in their assignment and give feedback; however, they mostly did not pay attention to the feedback received. Additionally, cognitive expressivity received high scores. Cognitive expressivity was linked to the ability of the teaching assistant to develop and maintain a friendly learning environment in class, opportunities in class to ask questions, and the ability of the teaching assistant to answer students' questions. Low trust in the teaching assistant's capabilities lowered cognitive expressivity. It led some students to negative expressions of engagement, such as not attending the class and not participating in the task.

Various aspects related to the other dimensions of APAG also informed students and affected their experience of the interaction. In particular, individuality formed the gestalt of the interaction. Emerging from data, students linked the emphasis on individual work to the individual exam format, limited time for interaction with peers in class, blind review processes, little visualisation of the social processes in the digital system, limited use of feedback, and lack of structured interactions with peers to develop student contributions or to provide feedback. While opportunities for socialisation were perceived to be available to a medium extent, student statements reflect that the opportunities were constituted through individual commitment and social practices extending time and context. Hence, sociality was mainly formed by prior established practices. 
Exposure and persistence represent aspects related to the perceived setting of the task. In the exposure dimension, students perceived their contributions to be visible to themselves, less visible to educators, and even less so to peers. In the persistence dimension, students generally perceived that they, peers, and educators could assess prior interactions and outcomes of interactions to a great extent. In specific, students perceived that the educator had better access to student contributions than anyone else.

\section{How do students' agency experiences develop}

The mean values of most of the included dimensions decreased from the beginning of the course to the end of the course, besides the opportunity for cognitive expressivity, exposure towards peers, and persistence towards educators. The gap between perceived opportunity and students' approaches generally increased at the end of the course; however, the difference within the dimension of sociality was stable. Scores of investment (opportunity and approach) were relatively high at the beginning and the end of the course.

Table 2. Total sample means for the participatory dimensions

\begin{tabular}{|c|c|c|c|c|c|c|c|c|}
\hline & \multicolumn{2}{|c|}{ Investment } & \multicolumn{2}{|c|}{ Sociality } & \multicolumn{2}{|c|}{$\begin{array}{l}\text { Cognitive } \\
\text { expressivity }\end{array}$} & \multicolumn{2}{|c|}{$\begin{array}{l}\text { Emotional } \\
\text { expressivity }\end{array}$} \\
\hline Dimension & $\begin{array}{l}\text { Opportunit } \\
\text { y }\end{array}$ & $\begin{array}{l}\text { Approac } \\
\text { h }\end{array}$ & $\begin{array}{l}\text { Opportunit } \\
\text { y }\end{array}$ & $\begin{array}{l}\text { Approac } \\
\text { h }\end{array}$ & $\begin{array}{l}\text { Opportunit } \\
\text { y }\end{array}$ & $\begin{array}{l}\text { Approac } \\
\mathrm{h}\end{array}$ & $\begin{array}{l}\text { Opportunit } \\
\text { y }\end{array}$ & $\begin{array}{l}\text { Approac } \\
\text { h }\end{array}$ \\
\hline $\begin{array}{l}\text { Mean at } \\
\text { the } \\
\text { beginnin } \\
\text { g of } \\
\text { the } \\
\text { course }\end{array}$ & 4 & 3.9 & 3.1 & 2.9 & 3.6 & 3.2 & 3 & 2.3 \\
\hline $\begin{array}{l}\text { Mean at } \\
\text { the } \\
\text { end of } \\
\text { the } \\
\text { course }\end{array}$ & 3.9 & 3.3 & 2.9 & 2.7 & 3.8 & 3.1 & 3 & 1.8 \\
\hline
\end{tabular}

\begin{tabular}{|l|l|l|l|l|l|l|}
\hline & \multicolumn{3}{|c|}{ Exposure } & \multicolumn{3}{c|}{ Persistence } \\
\hline Dimension & Oneself & Peers & Educator & Oneself & Peers & Educator \\
\hline $\begin{array}{l}\text { Mean at the } \\
\text { beginning of } \\
\text { the course }\end{array}$ & 4.3 & 1.6 & $2.4^{*}$ & 4.4 & $4.1^{* *}$ & 4.3 \\
\hline $\begin{array}{l}\text { Mean at the } \\
\text { end of the } \\
\text { course }\end{array}$ & 4.1 & 1.8 & $2.9 *$ & 4.3 & 4 & 4.8 \\
\hline
\end{tabular}

Note. Mean values are based on nine respondents for each dimension.

* Based on seven respondents due to lack of rating.

**Based on eight respondents due to lack of rating.

\section{The relation between agency experiences and participation}

To explore links between student participation and students' agency experiences, student participation was mapped into three categories based on the registration of students' digital behaviour:

a) Students who participated in all tasks and provided the expected amount of feedback.

b) Students who participated in all tasks, without providing the expected amount of feedback in at least one of the sessions.

c) Students who did not participate in at least one of the tasks and did not provide the expected amount of feedback in at least one of the feedback sessions.

Table 3 illustrates the mean values for each dimension in the beginning and at the end of the course related to each pattern of participation. Students' agency experiences were limited to include the investment, sociality, and expressivity dimensions. 
Pattern A comprises four students. Students associated with the pattern rate opportunities for investment as high at the beginning and the end of the course. Their rating is stable throughout the course. While less high, the rating of their approaches to investment is stable. Opportunities for sociality as well as approaches to sociality are rated to be low to medium. While both aspects increase at the end of the course, the dimension continues to be present to a low-medium degree. Opportunities for emotional expressivity receive high ratings at the beginning of the course but drops to a medium degree at the end of the course. Pattern A students' approaches to emotional expressivity begin low and end (even) lower. In contrast, opportunities for cognitive expressivity is stable and high. Students' approach to cognitive expressivity is stable but lower than the perceived opportunities.

Pattern B comprises one student. The particular student provides stable scores of the dimensions from the beginning to the end of the course. Significantly, the student provides low-medium ratings of every dimension, besides one. The student scores opportunities and approach to cognitive expressivity as high at the end of the course. Social and emotional aspects receive the lowest scores.

Three students are associated with pattern C. Students within the group score perceived opportunities and their approaches to investment as medium to high throughout the course. While students' approaches to investment decrease at the end of the course, their perception of opportunities for investment increases. Opportunities for sociality receive a high score at the beginning of the course but decrease significantly at the end of the course. While receiving a medium score initially, students' approaches to sociality likewise decrease during the course. Opportunities for emotional expressivity increase within this group of students from low-medium to a mediumhigh. By contrast, students' approaches to emotional expressivity begin with a medium evaluation and drop to a low rating. Finally, pattern $\mathrm{C}$ comprises a medium score of cognitive expressivity opportunities that increases at the end of the course. Approaches to cognitive expressivity receive a medium rating and decrease slightly at the end of the course.

Table 3. Comparison of student participation and students' ratings of investment, sociality, and expressivity

\begin{tabular}{|c|c|c|c|c|c|c|c|c|c|}
\hline & & \multicolumn{2}{|c|}{ Investment } & \multicolumn{2}{|c|}{ Sociality } & \multicolumn{2}{|c|}{$\begin{array}{l}\text { Emotional } \\
\text { expressivity }\end{array}$} & \multicolumn{2}{|c|}{$\begin{array}{l}\text { Cognitive } \\
\text { expressivity }\end{array}$} \\
\hline & $\begin{array}{l}\text { Interview } \\
\text { round }\end{array}$ & 1 & 2 & 1 & 2 & 1 & 2 & 1 & 2 \\
\hline \multirow[t]{2}{*}{ Pattern A } & Opportunities & 4,3 & 4,3 & 2,8 & 3,3 & 4,0 & 3,0 & 4.0 & 4.0 \\
\hline & Approach & 3,8 & 3,8 & 3,0 & 3,3 & 2,3 & 1,8 & 3,0 & 3,0 \\
\hline \multirow[t]{2}{*}{ Pattern B } & Opportunities & 3 & 3 & 2 & 2 & 1 & 2 & 3 & 4 \\
\hline & Approach & 3 & 3 & 2 & 2 & 1 & 2 & 3 & 4 \\
\hline \multirow[t]{2}{*}{ Pattern C } & Opportunities & 3,7 & 4,0 & 4,3 & 2,7 & 2,7 & 3,7 & 3,3 & 3,7 \\
\hline & Approach & 4,3 & 3,3 & 3,3 & 2,0 & 2,7 & 1,7 & 3,3 & 3,0 \\
\hline
\end{tabular}

Note. One student is excluded from this sample due to restricted permission to make use of the participant's digital data. Interview round 1 refers to the interviews conducted at the beginning of the course. Interview round 2 relates to the interviews conducted at the end of the course.

\section{The relation between the agency experience and academic performance}

The analysis did not identify a direct link between students' agency experiences and students' academic performance. In other words, high scores of the participatory experience do not seem to be linked directly to high student performance. Based on a mapping of students in three categories comprising a) students receiving high grades, b) medium grades, or c) low grades, however, showed that students receiving low grades tended not to differentiate between opportunities and their actual approach at the end of the course. As such, these students $(n=2)$, on average, viewed opportunities and approaches as similar or almost similar. By contrast, students receiving a medium grade $(n=3)$ differentiated between opportunities and approaches within three out of four dimensions (on average with 0.6 points). Finally, students $(n=4)$ receiving a high grade differentiated between opportunities and approaches in all four dimensions at the end of the course, and, significantly, with 1.0 point difference in average.

\section{The relation between participation and academic performance}


The mapping of grades with types of participation (Table 4) illustrates that the majority of high scoring students participated successfully in the digital teaching-learning interaction (pattern A). One high scoring student made use of pattern C. Medium scoring students adopted pattern B. Low scoring students followed pattern C, comprising less successful participation in the interaction.

Table 4. Comparison of participation and students' academic performance

\begin{tabular}{|l|l|l|l|}
\hline Types of participation & Low grade & Medium grade & High grade \\
\hline Pattern A & 0 & 1 & 3 \\
\hline Pattern B & 0 & 1 & 0 \\
\hline Pattern C & 2 & 0 & 1 \\
\hline $\begin{array}{l}\text { Note: One student is excluded from this sample due to restricted permission to make use of the participant's } \\
\text { digital data. }\end{array}$ \\
\hline
\end{tabular}

\section{Conclusion and discussion}

Drawing on data from interviews with students who participated in a first-semester course involving online peer assessment, the study captures and explores the ways students' agency in the digital interaction links to student participation and academic performance.

First, data suggest that interactions can be described as having a particular participation gestalt that inform student meaning-making. Overall, the gestalt seems to be relatively stable. In this study, students' participatory experience of the interaction stressed individual work, investment and cognitive expressivity. Social learning elements did not emerge to students as critical to the success of the interaction.

Second, while the study illustrates the challenging task of identifying clear links between agency in digital interactions, student participation and academic achievement within a small sample of students, the findings of this study draw attention to two possible patterns: a) Students that receive high grades seem to comply with instructional expectations of student participation. High-scoring students, however, negotiate their agentic orientation in the teaching-learning interaction in relation to perceived opportunities for investment. Hence, their investment in the interaction is lower than the perceived opportunities for investment. Besides, the group of students appears to hold stable views on opportunities and approaches to investment throughout the course. b) Students that receive low(er) grades seem to deviate from instructional expectations of student participation. This group of students was seen to converge perceived opportunities for agency with their agentic orientation, at least at the end of the course. Hence, individual options for 'doing something differently' in a particular interaction and for negotiating the quality of engagement appear to be limited. Finally, students receiving lower grades seem to hold less stable agency experiences of cognitive aspects compared to the group with higher grades.

What are the implications of the study for digital education or research into educational technologies? The study investigates an educational context involving student-centred teaching practices and a learning environment that ticks-off many of the premises of SCLE (Damsa \& de Lang, 2019). Examining students' agency experience from a relational perspective, however, suggests that assuming SCL by drawing on general descriptions of social learning interactions and technological affordances for sharing and communicating is inadequate for evidencing student-centredness. Developing a better understanding of participation from a student perspective is vital to qualify digital educational practices offered to students.

Finally, the results suggest additional lines of research. Research might explore how students' agency on a course level links to agency experiences in particular interactions and discuss how agency in courses or programmes reflects students' professional agency. Investigating other educational contexts and different types of digital interactions could also probe new insights and research questions.

\section{References}

Burkitt, I. (2016). Relational agency: Relational sociology, agency and interaction. European Journal of Social Theory, 19(3), 322-339. 
Dalsgaard, P., Halskov, K., \& Iversen, O. S. (2016). Participation gestalt: Analysing participatory qualities of interaction in public space. Paper presented at the Proceedings of the 2016 CHI Conference on Human Factors in Computing Systems.

Damşa, C., \& de Lange, T. (2019). Student-centred learning environments in higher education. Uniped, $42(01), 9-26$.

Damşa, C., \& Jornet, A. (2016). Revisiting Learning in Higher Education--Framing Notions Redefined through an Ecological Perspective. Frontline Learning Research, 4(4), 39-47.

Eteläpelto, A. (2017). Emerging conceptualisations on professional agency and learning. In Agency at Work (pp. 183-201): Springer.

Eteläpelto, A., Vähäsantanen, K., Hökkä, P., \& Paloniemi, S. (2013). What is agency? Conceptualising professional agency at work. Educational Research Review, 10, 45-65.

Giddens, A. (1984). The constitution of society: outline of the theory of structuration. Oxford: Polity Press. Goffman, E. (1955). On face-work: An analysis of ritual elements in social interaction. Psychiatry, 18(3), 213-231.

Goller, M., \& Paloniemi, S. (2017). Agency at work: Springer.

Halskov, K., \& Hansen, N. B. (2015). The diversity of participatory design research practice at PDC 2002- 2012. International Journal of Human-Computer Studies, 74, 81-92.

Jääskelä, P., Heilala, V., Kärkkäinen, T., \& Häkkinen, P. (2020). Student agency analytics: Learning analytics as a tool for analysing student agency in higher education. Behaviour \& Information Technology, 1-19.

Jääskelä, P., Poikkeus, A.-M., Häkkinen, P., Vasalampi, K., Rasku-Puttonen, H., \& Tolvanen, A. (2020). Students' agency profiles in relation to student-perceived teaching practices in university courses. International Journal of Educational Research, 103, in press.

Kirkwood, A., \& Price, L. (2014). Technology-enhanced learning and teaching in higher education: what is 'enhanced'and how do we know? A critical literature review. Learning, Media and Technology, 39(1), 636.

Klemenčič, M. (2017). From Student Engagement to Student Agency: Conceptual Considerations of European Policies on Student-centred Learning in Higher Education. Higher Education Policy, 30(1), 69-85.

Lim, Y.-k., Stolterman, E., Jung, H., \& Donaldson, J. (2007). Interaction gestalt and the design of aesthetic interactions. Paper presented at the Proceedings of the 2007 conference on Designing pleasurable products and interfaces.

Luo, H., Yang, T., Xue, J., \& Zuo, M. (2019). Impact of student agency on learning performance and learning experience in a flipped classroom. British Journal of Educational Technology, 50(2), 819-831.

Miles, B. M., Huberman, A. M., \& Saldana, J. (1994). Qualitative Data Analysis - A Methods Sourcebook. 3rd ed. Washington DC, USA: Sage.

OECD. (2018). The future of education and skills: Education 2030. In: Directorate for Education and Skills, OECD Paris, France.

Packer, M. J., \& Goicoechea, J. (2000). Sociocultural and constructivist theories of learning: Ontology, not just epistemology. Educational Psychologist, 35(4), 227-241.

Selwyn, N. (2016). Digital downsides: exploring university students' negative engagements with digital technology. Teaching in Higher Education, 21(8), 1006-1021.

Soini, T., Pietarinen, J., Toom, A., \& Pyhältö, K. (2015). What contributes to first-year student teachers' sense of professional agency in the classroom? Teachers and Teaching, 21(6), 641-659.

Stenalt, M. H., and Lassesen, B. (2017). An Exploratory Study of Undergraduate Law Students' Experience of Online Peer and Self-Grading: Towards an Experiential Perspective. In: Proceedings of the 2nd EuroSoTL Conference, Lund, Sweden, 239-244.

Stenalt, M. H. (2020). Researching student agency in digital education as if the social aspects matter: students' experience of participatory dimensions of online peer assessment. Assessment \& Evaluation in Higher Education, 1-15. in press.

Sun, S. Y., \& Goodyear, P. (2020). Social co-configuration in online language learning. Australasian Journal of Educational Technology, 36(2), 13-26.

Toom, A., Pietarinen, J., Soini, T., \& Pyhältö, K. (2017). How does the learning environment in 
teacher education cultivate first year student teachers' sense of professional agency in the professional community? Teaching and Teacher Education, 63, 126-136.

Tsai, Y.-S., Perrotta, C., \& Gašević, D. (2019). Empowering learners with personalised learning approaches? Agency, equity and transparency in the context of learning analytics. Assessment \& Evaluation in Higher Education, 1-14.

Hvid Stenalt, M. (2020). Investigating links between students' agency experiences in digital educational interactions, participation and academic performance. In S. Gregory, S. Warburton, \& M. Parkes (Eds.), ASCILITE's First Virtual Conference. Proceedings ASCILITE 2020 in Armidale (pp. 273-281). https://doi.org/10.14742/ascilite2020.0146

Note: All published papers are refereed, having undergone a double-blind peer-review process.

The author(s) assign a Creative Commons by attribution licence enabling others to distribute, remix, tweak, and build upon their work, even commercially, as long as credit is given to the author(s) for the original creation.

(c) Hvid Stenalt, M. 2020 